\title{
(Q) Future of clinical leadership: saving our greatest OPEN ACCESS intensity for human beings
}

\author{
Marc Harrison
}

Intermountain Health Care, Salt Lake City, Utah, USA

\section{Correspondence to}

Dr Marc Harrison, Intermountain Health Care, Salt Lake City, Utah 84111, USA; amhmd@imail.org

Received 9 June 2017 Revised 10 July 2017 Accepted 13 July 2017 Published Online First 8 August 2017

Check for updates

To cite: Harrison M. BMJ Leader 2017:1:13-15.

\section{ABSTRACT}

Do the qualities that distinguish good doctors always lead to success in the operational space? The few studies that have explored this question suggest they can, though it's not a guarantee, and there may be a tension. This article looks at the studies and suggests that with the global healthcare landscape changing so rapidly — politically, economically and technologicallyintroducing physicians to the craft of leadership in the operational space may be more important than ever. It can also be more rewarding than ever, so long as clinicians don't lose sight of what it is they can uniquely offer as physician leaders. The article concludes that clinicians may be uniquely positioned to connect important points being raised about the healthcare ecosystem back to the reason it exists in the first place: to support caregivers in the sacred act of healing the sick, of preserving human life and human potential. 'Saving our greatest intensity for human beings' is ultimately what must distinguish clinical leaders.

'I heard you were a pretty good intensivist.' That happened to be the first thing one paediatrician said to me last October when I was introduced to him as the new CEO of Intermountain Healthcare. His earnest tone suggested he wasn't trying to flatter me or offer a secondhand assessment of my professional skills. In fact, past experience had taught me that what this doctor really wanted to convey was how much it mattered to him that the new CEO of the place where he'd be dedicating his talents and huge quantities of his time knew what it meant to walk the walk.

Are physicians right to care if enterprise leaders have clinical expertise? Perhaps they are. This wasn't the first time I'd encountered doctors and nurses, and even non-clinicians with a stake in the game, who seemed convinced there was-or could be-a correlation between a good doctor and a strong leader of a healthcare enterprise. Leadership positions for physicians can happen almost by accident. They did for me. I wasn't seeking to be more than the best critical care paediatrician I could be when I was asked to become medical director of the paediatric intensive care unit (PICU) at the Cleveland Clinic. That led to other leadership roles including Chief Medical Operations Officer and CEO of Cleveland Clinic Abu Dhabi and finally $\mathrm{CEO}$ of Intermountain. Whatever the position, colleagues seemed to fully put their trust in me only when they saw that what mattered to me as a practising critical care paediatrician still mattered when I became responsible for the operations and strategic direction of a hospital or health system.
I also learnt it's not enough just to have a medical degree; the more important question was: 'Are you a good practitioner of your medical craft?' Of course, ideas about what makes a good doctor are fairly universal. Good doctors put patients first and advocate for them. They know their science and get good outcomes. Good doctors are compassionate and always have the courage to do the right thing. And, though sometimes obscured in the iconic conceptions of 'heroic' doctors, I would also argue that great clinicians have a deep understanding and unassailable faith in the potential of high-performing teams over individual stars. The best doctors today bring a tenacity to building great teams, and they find ways to optimise the skills of superstars and balance them with the very best that everyone on the team has to offer. And they keep the focus where it should be, on the patient.

Do the qualities that distinguish good doctors always lead to success in the operational space? The few studies that have explored this question suggest they can, though it's not a guarantee, and there may be a tension. A 2011 study that considered rankings by U.S. News \& World Report found that hospitals run by physicians had higher clinical quality. ${ }^{1}$ Another study, focused on management quality and conducted by researchers from Stanford, Harvard and the London School of Economics, showed that 'hospitals with a greater fraction of managers who are clinically trained obtained higher scores'. ${ }^{2}$ Looking more broadly than healthcare, a 2014 study that formed the basis of an article in the Harvard Business Review demonstrated that 'a boss's technical competence is the single strongest predictor of a worker's well-being' ${ }^{3}$ The researchers concluded that 'employees are far happier when they are led by people with deep expertise in the core activity of the business'. ${ }^{4}$ It makes sense that simply knowing your administrative leader has clinical expertise might help combat the cynicism that can naturally arise around decisions that change the way work is done. No doubt it's easier to be open when you know your boss knows what you know. And it gives the decision-maker better insight into how to communicate those decisions. It's also not surprising that even external stakeholders take comfort in knowing executives at the top were, first, good physicians. ${ }^{5}$

So, is there a tension in moving from the exam room, or the operating room (OR), to the C-suite? There can be. In recent years I've had the chance to meet up with healthcare thought leaders, C-suite hospital and health system executives, and leaders of related enterprises at various conferences and events. These events are organised so we can learn from each other, and I'm always impressed by the level of expertise of the participants. I can't help 
noticing, though, that increasingly these discussions focus largely on markets, market share, mergers, joint ventures, cost pressures and competition-in other words, the money stuff. The financial realities and challenges are daunting, to be sure, but is this focus the future of clinical leadership? If so, it may be a bleak one. In an article published first here in 2015 entitled 'The quadruple aim', the authors raise red flags about the 'gradual shift in healthcare from a public service to a business model that occurred in the latter half of the $20^{\text {th }}$ century', warning that 'complex, intimate caregiving relationships have been reduced to a series of transactional demanding tasks', which they say has resulted in work that is less effective and robbed of its meaning and joy. ${ }^{6}$

Is that inevitable? I don't think so. I'm a relentless optimist, and I believe that with the global healthcare landscape changing so rapidly_politically, economically and technologically-introducing physicians to the craft of leadership in the operational space is more important than ever. And it can be more rewarding than ever, so long as we don't lose sight of what it is we can uniquely offer as physician leaders. One of the recent meetings I participated in had a roundtable with a number of exemplary industry executives as panellists, of whom about $75 \%$ were non-clinicians. As we talked about our concerns they offered powerful insights, but as we were well into the conversation, it occurred to me that no one had yet mentioned the patient. I realised my small contribution could be to connect important points being raised about the healthcare ecosystem back to the reason it exists in the first place: to support caregivers in the sacred act of healing the sick, of preserving human life and human potential. Exercising great care over budgets and balance sheets is essential because it enables us to do good work, but we should always save our greatest intensity for our patients, for our caregivers, for human beings. Along the way all healthcare leaders, including clinical leaders, will need to create and implement sound strategies and make brave business decisions, but no matter where our careers take us, or how expansive our spans of control, what keeps us up at night should be what keeps all good doctors and nurses up at night: 'Have we harmed a patient?' 'Did people get the right care, delivered at the right time and in the right way?' 'Did everyone have access to the care they needed?' 'Are we being good stewards of limited resources, or are we wasting our patients' money?'

So how can our focus on patients help enable sound business strategies? And what else is necessary for effective clinical leadership? A number of critical competencies are becoming increasingly important. As mentioned, to be effective clinical leaders we must possess a resolute team orientation and translate that into an ability to lead high-performing multidisciplinary teams. Recognising and embracing the reality that 'it's not all about me' opens the way for a strengths-based approach to leadership. Trusting others may not come naturally to high achievers, but it's essential to enterprise success. When I accepted the position in Abu Dhabi, I was the fifth CEO in five years. The dream was to bring the Cleveland Clinic's model of care to the region and help realise the vision of the Abu Dhabi government to develop a world-class healthcare infrastructure that could greatly reduce the need for people in the region to leave family and loved ones to travel abroad for high-quality care. Because realising this dream had eluded the four CEOs who came before me, I was ribbed by colleagues about being 'banished'. I was thrilled by the challenge. An early step was seeking to learn from the experience of leaders outside the healthcare industry who'd had proven success with global integration in other industries. Still, the linchpin was recruiting and marshalling a broad, deep, diverse team with great talent. It took all of us to successfully replicate the first-ever US multispecialty hospital outside North America-establishing 12 institutes, 5 centres of excellence and $>30$ medical and surgical specialties. What made it thrivedespite a host of difficult challenges-was putting trust in the team. It meant letting decisions be informed by those with more directly applicable experience, more cultural sensitivity, the best ideas-regardless of titles or spans of control. Healthcare plucks common chords in all of us-man or woman, Muslim, Christian, Jewish, Hindu, Buddhist or Taoist-we all want good things like health and well-being. To see people in abayas and andoras talking and learning and laughing with blue-eyed people in Western dress showed that letting go of a tight hold on reins-listening and inviting others to lead-really can be the best way, ultimately, to fully hold and live up to our own distinct responsibilities.

Putting patients at the centre requires another competency that may not seem intuitive-especially if being a great clinician was the currency that brought leadership opportunities knocking. That competency is the ability to take a look at things that created success in the past-and reimagine them to give patients what they need and want now. It's axiomatic that healthcare has been designed for the comfort and convenient of providers-especially, perhaps, in the USA. Sometimes, that 'sovereign profession' attitude-to use Paul Starr's famous phrase ${ }^{7}$ - works to hinder innovation and imagination and ties us to the status quo. For example, some professional specialties have functioned more like guilds, tightly controlling and limiting access to training. Self-preserving strategies of controlling supply as a way of guaranteeing demand won't help us serve populations affordably. And historically, hospitals in the USA have focused largely on trying to attract patients to our facilities, rather than taking care out to people where they live, work and play. We're woefully behind the times in using digital and other tools to improve service. What it means to be customer-centric is changing, and leadership requires being agile in adapting to those changes. What it means to expand access is also changing. Technologies and computing capabilities are transforming our ability to share subspecialty expertise across vast distances, enabling local physicians to care for patients close to home. New payer-provider models are presenting challenges, especially as we grapple with how to make these models economically viable for patients, payers and talented providers, but we know highquality healthcare can't be available to everyone without them. Moving away from models that reward volume and towards payment for value is the key to affordability, and affordability is key to access. Caring for our patients' economic well-being is caring for patients. Data are helping us discover better ways to treat patients, and physician leaders are helping connect that data to humanity by 'showing' rather than 'telling' colleagues how variations in treatment can lead to suboptimal outcomes and helping systems scale evidence-based practices. New technologies also mean we have the chance to involve patients more directly in creating health for themselves and in making healthcare decisions that meet their goals.

We don't have all the answers yet, but models that improve the health of populations can and should create a virtuous cycle, one that ultimately helps us deliver care that is both more universally available and more personalised, than ever before. Physicians, with our medical expertise, can champion these efforts, refine and improve them.

The characteristics of great leaders are often exhibited by clinicians who don't aspire to administrative work. These clinicians create cultures that inspire those around them, and that's also leadership. I was recently told about a cosmetic surgeon at 
Intermountain Healthcare who does a good deal of restorative work in his practice. This surgeon recognised that many members of his team in the OR only rarely got to see the outcome of the work they do. So he makes it routine to take a little time out in every surgery to tell the team a little of the patient's story, especially something about the patient's hopes and dreams. 'Won't it be great when Mrs. Smith gets to enjoy eating corn on the cob with her grandkids at the family reunion this summer?' With that simple technique the surgeon ensures that no procedure is ever routine.

I learnt from my grandfather and my father-both surgeonswhat it means to stay connected to mission. I used to go with my dad sometimes to the hospital on Saturdays, probably because I was annoying at home. There was one hospital he particularly loved. It was in a dying steel town-Homestead, Pennsylvania. I remember going there with him when I was about 10 years of age, and it seemed to me something was different there than compared with other hospitals. He knew everybody. He knew people in the emergency room, he knew the people sweeping the floors. One day I asked him, 'Why do you like it here so much?' He told me he felt like he was making a difference. He said, 'Well, the people here are poor. If I don't take care of them, who will?' And that just really struck me, and it stayed with me. What I heard was, if you go into healthcare and you do the right thing, you can really make an impact. That experience with my father continues to shape my experience today. Early on in my career I went through a 'super doer' phase, where I tried to identify a problem in the intensive care unit at Cleveland Clinic and fix it. Over time, though, my mindset became more about understanding 'how does this all fit together?' How can I take whatever talents I have and create a unified experience for all patients, and make a difference in the communities we're in?

As we go forward and bring our best thinking to the growing challenges of ageing populations, cost pressures and geopolitical forces beyond our control, principle-based leadership will be more valuable than ever before. The desire to do good that drew us to medicine and made us good clinicians can also define us as leaders. Our patient-centred focus can create enterprise-wide cultures that put a high value on listening and connecting to a clear mission. When it works, there is a sort of nirvana. It doesn't always happen. There are some physician leaders who fail, and there are some really phenomenal non-physician leaders. With the enormous demand for great business acumen in our specialties and service lines, our local hospitals and clinics, and in healthcare globally, all leaders are called to honour first and foremost the human beings who are putting their lives in our hands. In a revealing moment in Jonathan Safran Foer's novel Here I Am, a government spokesperson is pressed by a journalist to quantify the number of casualties after a massive earthquake in Israel. 'One is ten thousand too many', the official answers. Reserving our greatest intensity for what happens to our patients, making it our starting point and our final destination, is what will set clinical leaders apart. Not only that, it will bring joy and meaning to our work, and change the world for the better.

Competing interests None declared.

Provenance and peer review Commissioned; internally peer reviewed.

Open Access This is an Open Access article distributed in accordance with the Creative Commons Attribution Non Commercial (CC BY-NC 4.0) license, which permits others to distribute, remix, adapt, build upon this work non-commercially, and license their derivative works on different terms, provided the original work is properly cited and the use is non-commercial. See: http://creativecommons.org/ licenses/by-nc/4.0/

(c) Article author(s) (or their employer(s) unless otherwise stated in the text of the article) [year]. All rights reserved. No commercial use is permitted unless otherwise expressly granted.

\section{REFERENCES}

1 Advisory Board Daily Briefing. What many top-ranked hospitals have in common: physicians in the C-Suite. https://www.advisory.com/daily-briefing. (accessed 31 May 2017).

2 Bloom N, Sadun R, John VR. Does management matter in healthcare? NBER 2014.

3 Artz B, Goodall A, Oswald AJ. Boss competence and worker well-being: NBER, 2014.

4 Advisory Board Daily Briefing. What many top-ranked hospitals have in common: physicians in the C-Suite https://www.advisory.com/daily-briefing (accessed 31 May 2017).

5 Stoller SK, Goodall A, Baker A. Why the best hospitals are managed by doctors: Harvard Business Review, 2016. (accessed Dec 2016).

6 Sikka R, Morath JM, Leape L. The Quadruple Aim: care, health, cost and meaning in work. BMJ Qual Saf 2015;24:608-10.

7 Starr P. The social transformation of american medicine: the rise of a sovereign profession and the making of a vast industry. New York: Basic books, 1982. 